\title{
Treatment of HAE Attacks in the Icatibant Outcome Survey: An Analysis of Icatibant Self-Administration versus Administration by Health Care Professionals
}

\author{
Dolores Hernández Fernandez de Rojas ${ }^{a} \quad$ Ethel Ibañez $^{a} \quad$ Hilary Longhurst $^{c}$ \\ Marcus Maurer ${ }^{d}$ Vincent Fabien ${ }^{e}$ Werner Aberer ${ }^{f}$ Laurence Bouillet ${ }^{g}$ \\ Andrea Zanichelli ${ }^{\text {h }}$ Teresa Caballerob ${ }^{b}$ on behalf of the IOS Study Group \\ a Department of Allergy, IIS Hospital La Fe, Valencia, and ${ }^{b}$ Hospital La Paz Institute for Health Research, Biomedical \\ Research Network on Rare Diseases CIBERER U754, Madrid, Spain; ' ${ }^{\circ}$ epartment of Immunology, Barts Health NHS Trust, \\ London, UK; ${ }^{d}$ Department of Dermatology and Allergy, Allergie-Centrum-Charité, Charité-Universitätsmedizin, Berlin,

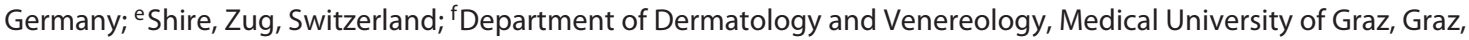 \\ Austria; ${ }^{9}$ National Reference Centre for Angioedema, Internal Medicine Department, Grenoble University Hospital, \\ Grenoble, France; ${ }^{\mathrm{h}}$ Dipartimento di Scienze Cliniche, Università degli Studi di Milano, Milano, Italy
}

\begin{abstract}
Key Words
Hereditary angio-oedema - Icatibant - Oedema . Self-administration - Icatibant Outcome Survey . C1 inhibitor deficiency - Bradykinin B2 receptor antagonist · Therapy
\end{abstract}

\begin{abstract}
Background: Icatibant, a selective bradykinin B2 receptor antagonist for the treatment of acute hereditary angio-oedema (HAE) attacks in adults, can be administered by health care professionals (HCPs) or self-administered. This analysis compared characteristics and outcomes of acute HAE attacks treated with self-administered and HCP-administered icatibant in a real-world setting. Methods: The Icatibant Outcome Survey (Shire, Zug, Switzerland; NCT01034969) is an international observational study monitoring the safety and effectiveness of icatibant treatment. Descriptive retrospective analyses were performed (February 2008 to December 2012). Results: Icatibant was used in 652 attacks in 170 patients with HAE type I/II. Most icatibant injections were self-
\end{abstract}

administered $(431 / 652,68.5 \%)$. The proportion of self-treated attacks increased over time $(40.3 \%$ in 2009 vs. $89.7 \%$ in 2012). The median time to administration was significantly shorter in self- versus HCP-treated attacks (1.5 vs. 2.4 h; $p=$ $0.016)$. Earlier treatment ( $<2 \mathrm{~h}$ after onset) was significantly associated with a shorter median time to resolution ( $2.5 \mathrm{vs}$. $5.0 \mathrm{~h} ; \mathrm{p}=0.032$ ) and attack duration ( 3.0 vs. $14.0 \mathrm{~h} ; \mathrm{p}<$ 0.0001 ), regardless of administration method. Patients selfadministered icatibant for attacks of all severities; overall, $34.7 \%$ of severe and $30.2 \%$ of very severe attacks were HCP treated. Logistic regression analysis did not find use of longterm prophylaxis, attack location or gender to be predictive for self-administration. Conclusions: The proportion of HAE attacks treated with self-administered icatibant increased over time. Patients successfully self-administered icatibant for a wide variety of HAE attacks, demonstrating that icatibant is generally well tolerated and effective for self-administration. Self-administration of icatibant provides a complementary option to HCP administration, enabling optimization of patient care.

(c) 2015 S. Karger AG, Basel

\begin{tabular}{ll}
\hline KARGER 125.s. & $\begin{array}{l}\text { () 2015 S. Karger AG, Basel } \\
1018-2438 / 15 / 1671-0021 \$ 39.50 / 0 \quad \text { Karger }\end{array}$ \\
$\begin{array}{l}\text { E-Mail karger@karger.com } \\
\text { www.karger.com/iaa }\end{array}$ & $\begin{array}{l}\text { This is an Open Access article licensed under the terms of the } \\
\text { Creative Commons Attribution-NonCommercial 3.0 Un- } \\
\text { ported license (CC BY-NC) (www.karger.com/OA-license), } \\
\text { applicable to the online version of the article only. Distribu- } \\
\text { tion permitted for non-commercial purposes only. }\end{array}$
\end{tabular}

Correspondence to: Dr. Dolores Hernández Fernandez de Rojas Department of Allergy, IIS Hospital La Fe Avda. Fernando Abril Martorell 126

ES-46026 Valencia (Spain)

E-Mail hernandez_dol@gva.es 


\section{Introduction}

Hereditary angio-oedema (HAE) is a rare autosomal dominant condition with an estimated prevalence of approximately 1:50,000 people [1]. HAE manifests as cutaneous or submucosal oedema, most commonly occurring in the abdomen, on the skin of the face, lips, tongue or extremities, and in the upper respiratory tract $[2,3]$. Attacks are recurrent and usually unpredictable, and symptoms can be severe $[2,4]$. Severe attacks may necessitate hospital admission [5], and laryngeal oedema can be fatal if the airways are compromised [6-8]. If left untreated, attacks may last for several days before resolving spontaneously $[2,4]$.

The most common aetiology of HAE involves either a deficiency (type I) or dysfunction (type II) of the C1 esterase inhibitor (C1-INH) [2, 4]. This deficiency in C1INH leads to overproduction of bradykinin and activation of bradykinin B2 receptors, which increases vascular permeability and results in oedema [9-12].

International consensus documents recommend ondemand therapy for HAE attacks, particularly those involving the face, abdomen or respiratory tract, and state that early treatment is desirable to reduce attack duration $[1,3,13,14]$. Furthermore, the World Allergy Organization 2012 guideline and Hereditary Angioedema International Working Group 2012 consensus report state that, where licensed indications permit, patients should be allowed to keep on-demand medication at home and taught to self-treat their acute HAE attacks [3, 13]. Indeed, given the association between early treatment and reduced attack duration, the development of treatment options for self-administration has been welcomed by patients and health care professionals (HCPs) alike [15].

The efficacy and safety of icatibant have been demonstrated in 3 phase III clinical trials: For Angioedema Subcutaneous Treatment (FAST)-1, -2 and $-3[16,17]$. Icatibant was first approved for symptomatic treatment of acute attacks of HAE in adults (with C1-INH deficiency) as an HCP-administered subcutaneous injection in Europe in 2008 [18]. In 2011, icatibant was approved in the USA for administration by HCPs and patients [19], and the European indication was updated to permit patient self-administration after training under the guidance of an HCP [18].

The aim of this analysis was to investigate and compare the effectiveness and safety of HCP- and self-administered icatibant, using real-world data collected from the Icatibant Outcome Survey (IOS), an ongoing long-term observational study [20].

\section{Materials and Methods}

\section{Study Design and Population}

The IOS (Shire, Zug, Switzerland; NCT01034969) is an ongoing, international, prospective, observational study that monitors the effectiveness and safety of icatibant during real-world use. Data are collected via physician-completed electronic forms at routine visits. By December 2012, 10 countries were included in the IOS programme: Austria, Denmark, France, Germany, Greece, Israel, Italy, Spain, Sweden and the UK. The IOS is conducted in accordance with the Declaration of Helsinki and the International Conference on Harmonization Good Clinical Practice guidelines. Approval was obtained from local ethics committees and/or health authorities, and all patients provided written informed consent. Details of the IOS study design and setting have been described previously [20].

Patients were eligible for inclusion in this analysis if they had been prescribed icatibant and had a diagnosis of HAE type I or II that was clinically confirmed by laboratory tests (C1-INH concentration and function). Patients attended regular follow-up visits, recommended every 6 months, in accordance with routine clinical practice.

Adverse events (AEs) recorded throughout the study were classified as not related, possibly related or probably related to icatibant treatment, as judged by the study investigator. Where data for the classification of the relationship of the AE to treatment were missing, AEs were considered related to icatibant treatment.

\section{Patients}

IOS data were available for 368 patients who experienced 1,213 HAE attacks between February 2008 and December 31, 2012. Of these, 652 attacks in 170 patients were treated with icatibant and were included in this analysis. In summary, patients were recruited at 36 centres; the majority of patients were female $(104 / 170,61.2 \%)$, the median age was 39.6 years (range 16.5-79.0 years), and most patients had a diagnosis of HAE type I (157/170, 92.4\%).

Data on patient demographics, HAE diagnosis, significant medical history and characteristics of the previous attacks were collected at patient enrolment by the attending doctor. During routine visits, a description of each attack was recorded, including site of attack, severity, treatment administration, method of administration (HCP or self-administration), time to treatment, time to resolution, concomitant medications and AEs.

For all HAE attacks, a description of the affected site (skin, abdomen, larynx and other organs) and the severity of the attack by a symptom score according to the interference with daily activities and the need of other countermeasures $(0=$ no symptoms, no interference; 1 = no or mild interference; 2 = moderate interference, no countermeasures required; 3 = severe interference with or without countermeasures; 4 = very severe interference and other countermeasures required) were recorded.

\section{Outcome Measures}

The focus of this analysis was to compare characteristics and treatment outcomes for HAE attacks treated with self- and HCPadministered icatibant. For the purposes of the analysis, self-administration included administration by a family member or nonprofessional carer. If the patient or family member was also an HCP, this injection was nevertheless classified as a self-administration. Attack characteristics, including severity, were evaluated by the patient and reported at regular follow-up visits. 
Outcome measures were time to treatment (defined as time from onset of attack to first icatibant injection), time to resolution (defined as time from injection to resolution of symptoms) and attack duration (defined as total time from onset of attack to symptom resolution).

\section{Statistical Methods}

Descriptive analyses of HAE attack characteristics and treatment outcomes for patients who received icatibant were performed retrospectively, including data for icatibant-treated attacks occurring prior to IOS entry. Attacks with missing data for a particular outcome were excluded from the analysis of that outcome. A mixed-model analysis of repeated measures (PROC MIXED; SAS Institute, Cary, N.C., USA) was used to compare time to treatment, time to resolution and duration of attack. The $\chi^{2}$ test (level of statistical significance of $\alpha=0.05$ ) was used to compare percentages. Data are presented as median (with interquartile range, IQR) or mean (with standard deviation).

Logistic regression analyses were conducted to identify any factors that might predict the preferred method of administration. The factors analysed were patient gender, attack location and use of long-term prophylaxis (LTP). A multivariate model was built using a backward selection process, incorporating variables from the univariate model with $p$ values $<0.20$ and removing factors with the highest $\mathrm{p}$ values until only significant factors remained $(\mathrm{p} \leq 0.05)$.

\section{Results}

\section{HAE Attack Characteristics and Treatment}

Overall, $91.9 \%$ of icatibant-treated attacks were in patients with HAE type I. The frequency of HAE attacks each patient experienced was highly variable, representing a spectrum from $<1$ attack per year $(7.7 \%)$ to at least 1 attack per week (7.7\%). Between these extremes, $8.2 \%$ of patients experienced 1-2 attacks per year, $23.5 \%$ experienced 3-6 attacks per year, 12.9\% experienced 7-11 per year and $29.4 \%$ experienced $12-51$ per year.

Of the 652 icatibant-treated attacks, 198 (31.5\%) were treated by an HCP whereas the majority (431 attacks, 68.5\%) were defined as self-treated (data not recorded for 23 attacks). Of the attacks defined as selftreated, icatibant was administered by a non-HCP individual other than the patient (e.g. family member or carer) in 31 attacks (7.2\%) but the majority of icatibant injections were self-administered by the patient (400 attacks, 92.8\%).

Most attacks were sufficiently treated with a single icatibant injection (87.2\% of self-treated attacks vs. $91.9 \%$ of HCP-treated attacks). Of attacks treated with self-administered icatibant, $12.8 \%$ were treated with a second or third injection compared with $8.1 \%$ of HCP-treated attacks $(\mathrm{p}=0.084)$.

Self- versus HCP Administration of Icatibant: Real-World Data
Table 1. Severity of icatibant-treated HAE attacks

\begin{tabular}{llcc}
\hline $\begin{array}{l}\text { Attack } \\
\text { severity }\end{array}$ & $\begin{array}{l}\text { Overall } \\
(\mathrm{n}=652)\end{array}$ & $\begin{array}{l}\text { HCP } \\
(\mathrm{n}=198)^{1}\end{array}$ & $\begin{array}{l}\text { Self-administration } \\
(\mathrm{n}=431)^{1}\end{array}$ \\
\hline Total & 613 & 192 & 413 \\
Missing & 39 & 6 & 18 \\
Mild & $41(6.7)$ & $5(2.6)$ & $35(8.5)$ \\
Moderate & $133(21.7)$ & $42(21.9)$ & $87(21.1)$ \\
Severe & $299(48.8)$ & $103(53.6)$ & $194(47.0)$ \\
Very severe & $140(22.8)$ & $42(21.9)$ & $97(23.5)$ \\
\hline
\end{tabular}

Data are numbers or numbers with percentages in parentheses. Total $=$ Total number of attacks with recorded severity classification.

${ }^{1}$ The administration method was not recorded for 23 attacks.

Analysing attack severity by administration type revealed that approximately two-thirds of attacks rated as moderate, severe or very severe were treated with selfadministered icatibant; $87.5 \%$ of mild attacks were also self-treated (table 1). Overall, attack severity was similar for HCP- and self-treated attacks: 75.5 versus $70.5 \%$, respectively, were rated as severe/very severe and 21.9 versus $21.1 \%$, respectively, were rated as moderate (table 1 ).

Analysis of attack location demonstrated that most cutaneous attacks $(148 / 213,69.5 \%)$ and abdominal attacks $(209 / 286,73.1 \%)$ were treated with self-administered icatibant. Just over half of laryngeal attacks $(17 / 31,54.8 \%)$ were self-treated and $45.2 \%(14 / 31)$ were treated by an HCP. Similarly, $71.0 \%$ of single-site attacks were treated by self-administration, compared with $51.3 \%$ of attacks at multiple sites.

Logistic regression analyses did not find LTP, attack location or gender to be significant predictors of self-administration.

\section{Treatment Administration}

Overall, icatibant was self-administered in $68.5 \%$ of recorded HAE attacks. The proportion of patients self-administering icatibant increased over time, compared with HCP administration: $89.7 \%$ of icatibant-treated attacks were self-treated in 2012, compared with only $40.3 \%$ in 2009 (fig. 1a). Just over half of the patients (54.7\%) received their first icatibant injection from an HCP. Analysing treatment administration for repeat attacks demonstrates that patients were increasingly more likely to selfadminister icatibant for subsequent attacks, with $63.5 \%$ self-treating for their second attack, rising to $87.5 \%$ for the tenth attack (fig. 1b). 
Fig. 1. a Proportion of attacks self-treated with icatibant increased with time. b Selfadministration of icatibant increased with the number of attacks treated.

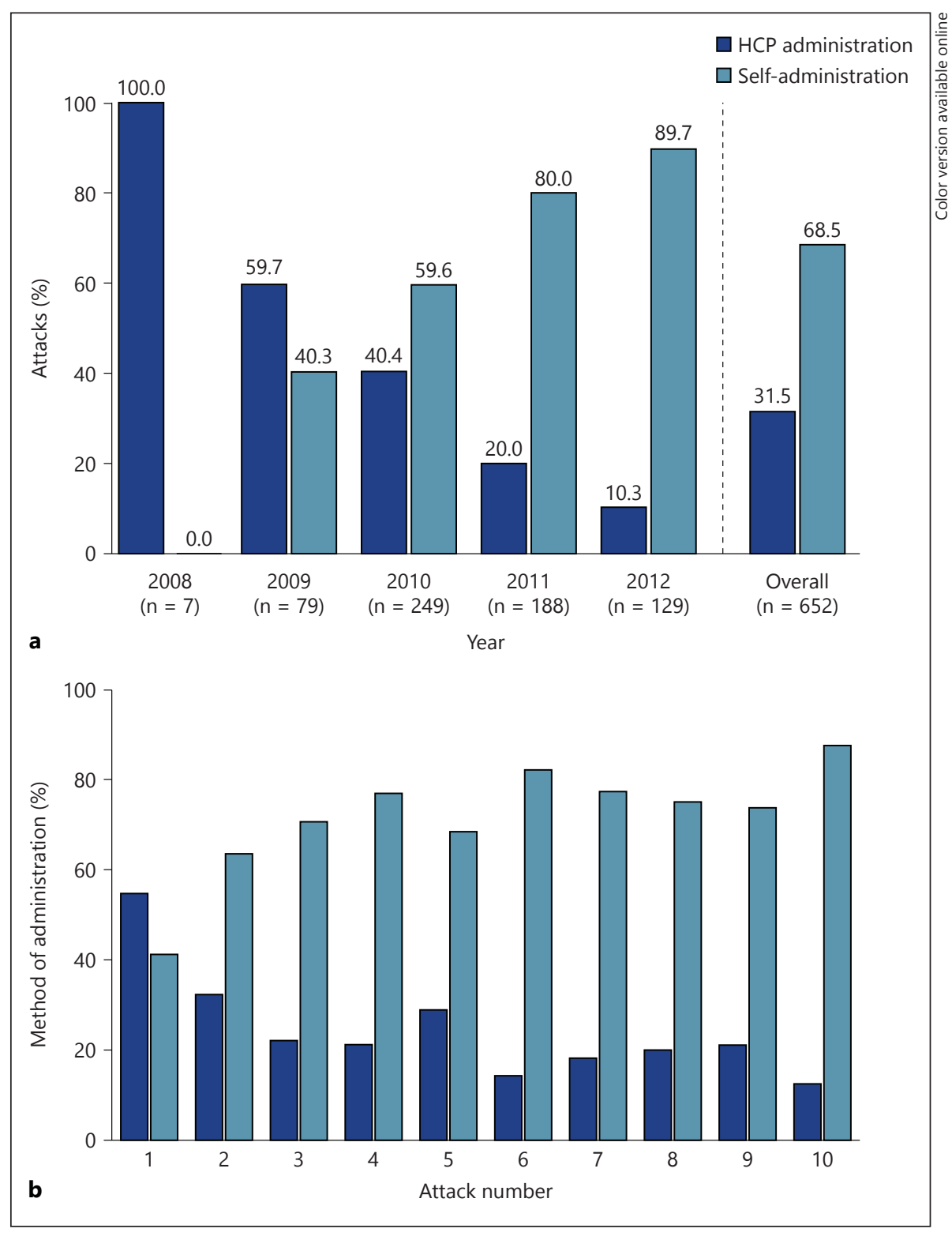

\section{Time to Administration}

The median time from the onset of an HAE attack to the first administration of icatibant was almost $1 \mathrm{~h}$ shorter for self-administration (1.5 h; IQR $0.5-5.0)$ compared with HCP administration (2.4 h; IQR 1.0-8.2; $\mathrm{p}=0.016)$. Similarly, significantly more attacks were treated within $1 \mathrm{~h}$ by self-administration than by HCP administration (37.8 vs. $20.2 \%$, respectively; $\mathrm{p}=$ 0.002; fig. 2a). Similar trends were observed in favour of self-administration for comparisons of treatment administration within $2 \mathrm{~h}$ and within $5 \mathrm{~h}$ ( $\mathrm{p} \leq 0.07$; fig. 2a). 


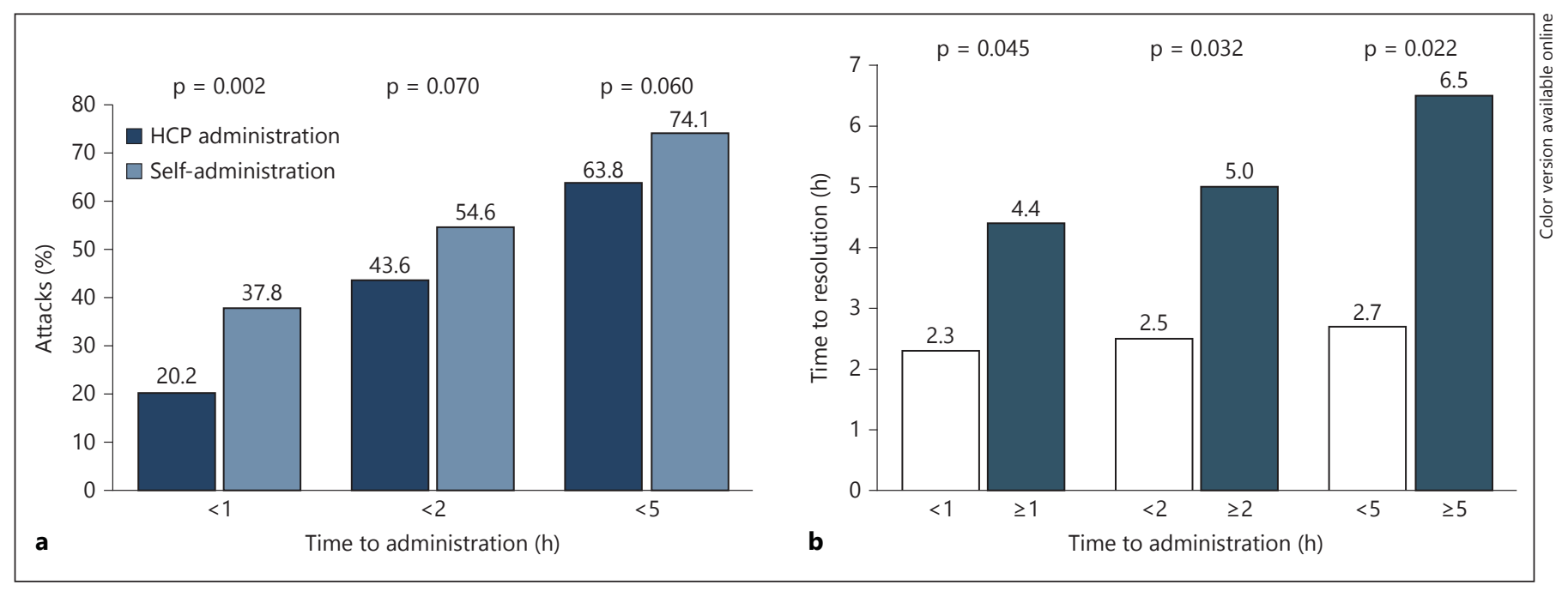

Fig. 2. a Self-administration of icatibant results in earlier treatment. Data shown are means. For HCP-administered icatibant, $\mathrm{n}=94$; for self-administered icatibant, $n=251$. b Early treatment with icati-

Table 2. Rescue medication used to supplement icatibant treatment of HAE attacks

\begin{tabular}{lcl}
\hline Rescue medication & $\begin{array}{l}\text { HCP } \\
(\mathrm{n}=47 ; 23.7 \%)\end{array}$ & $\begin{array}{l}\text { Self-administration } \\
(\mathrm{n}=103 ; 23.9 \%)\end{array}$ \\
\hline Analgesics & $9(19.1)$ & $11(10.7)$ \\
Antiemetics & $7(14.9)$ & - \\
Antifibrinolytics & $4(8.5)$ & $18(17.5)$ \\
Antihistamines & $2(4.3)$ & - \\
Anxiolytics & $2(4.3)$ & $1(0.97)$ \\
Attenuated androgens & $8(17.0)$ & $9(8.7)$ \\
C1-INH & $12(25.5)$ & $64(62.1)^{1}$ \\
Corticosteroids & $5(10.6)$ & - \\
Spasmolytics & - & $4(3.9)$ \\
Other & $8(17.0)$ & $7(6.8)$ \\
\hline
\end{tabular}

Data are numbers of attacks with percentages in parentheses.

${ }^{1}$ A total of 19 patients used C1-INH rescue medication; 46/64 self-treated attacks were recorded by a single patient.

Time to Symptom Resolution and Duration of Attack

There was no significant difference in the overall median time to resolution between self-treated and HCPtreated HAE attacks (3.4 h, IQR 1.0-9.5 h, vs. $3.5 \mathrm{~h}$, IQR 1.0-9.0 h, respectively). Early treatment was significantly associated with shorter times to resolution of symptoms ( $\mathrm{p}<0.05$ ), regardless of administration method (fig. 2b). The median duration of attack was similar for self- and HCP-treated attacks (7.4 h, IQR 2.8-16.0 h, vs. 8.5 h, IQR bant significantly reduced the median time to resolution, regardless of administration method. $\mathrm{n}=311$ attacks $(<1 \mathrm{~h}, \mathrm{n}=107 ; \geq 1 \mathrm{~h}, \mathrm{n}=$ $204 ;<2$ h, $\mathrm{n}=163 ; \geq 2$ h, $\mathrm{n}=148 ;<5$ h, $\mathrm{n}=224 ; \geq 5$ h, $\mathrm{n}=87$ ).

3.5-23.0 $\mathrm{h}$, respectively; $\mathrm{p}=0.147)$. Again, although there was no difference between self- and HCP administration, early treatment was associated with a significantly shorter duration of attack $(3.0 \mathrm{~h}$ for attacks treated $<2 \mathrm{~h}$ vs. $14 \mathrm{~h}$ for attacks treated $\geq 2 \mathrm{~h}$ after onset; $\mathrm{p}<0.0001)$. Similar results were observed for attacks treated $<1 \mathrm{~h}$ versus $\geq 1 \mathrm{~h}$ after onset and $<5 \mathrm{~h}$ versus $\geq 5 \mathrm{~h}$ after onset $(\mathrm{p}<0.0001$ for both).

\section{Safety}

Overall, 21 patients reported 38 AEs. Fourteen AEs considered possibly or probably related to icatibant were recorded in 4 patients: 6 events of injection site erythema in a single patient, and single events of chest discomfort, drug inefficacy, feeling hot, gastritis, decreased blood pressure, headache and depression; 1 event was unclassified. Thirteen patients each experienced 1 serious $\mathrm{AE}$ (SAE): 3 patients reported SAEs of pregnancy, and all other SAEs were individual events. One SAE was considered potentially treatment related (gastritis resulting in hospital admission). No cardiovascular or cerebrovascular AEs were recorded.

\section{Discussion}

Within the IOS population included in this analysis, there has been an increasing trend towards the self-administration of icatibant, which accounted for almost 
$90 \%$ of icatibant administrations in 2012 . This finding not only reflects the change in indication in 2011 to permit self-administration of icatibant in the European Union, but also suggests that HCPs are embracing current guideline recommendations that on-demand self-administration is desirable and patients should be trained accordingly $[3,13]$. Furthermore, the analysis demonstrates that patients become increasingly likely to self-administer icatibant with each subsequent attack, suggesting that patients are confidently adopting self-administration. These results are in agreement with those from a previously reported phase IIIb study of icatibant self-administration in patients who had previously received icatibant from an HCP [21]. The study not only concluded that patients are capable of recognizing an attack and treating it appropriately, but also demonstrated, using patient satisfaction data, that the majority of patients preferred self-administering icatibant to receiving it from an HCP [21]. Not only is self-administration of icatibant beneficial to patients in terms of reduced attack duration and improved quality of life $[15,22]$, it may also confer substantial economic benefits, both in terms of direct health care costs and indirect savings, as has been demonstrated in a Spanish study [23].

The distribution of attack location and severity of $\mathrm{HAE}$ attacks treated with icatibant were similar between HCPand self-administered injections, suggesting that there were no disease-related barriers to self-treatment. However, the proportion of mild attacks for which icatibant was self-administered was higher than for HCP administration. This perhaps reflects the fact that patients may not visit their HCP until an attack has developed to a certain severity. Notably, the higher number of mild attacks self-treated with icatibant reflects the recommendations in international consensus documents and guidelines that attacks be treated as early as possible $[3,13]$.

In the full analysis, there were no differences in the requirement for rescue medication between attacks treated with self- or HCP-administered icatibant. However, 2 patients displayed atypical treatment patterns resulting in high rates of re-injection and use of rescue medication that may have had undue impact on the analyses (1 patient experienced 54 icatibant-treated attacks, 27 requiring a second injection and 46 requiring C1-INH rescue medication; the other patient reported 32 icatibant-treated attacks but typically administered the first injection during the prodromal stage, outside approved use, and administered further injections once the attack had started). Excluding data for these 2 patients, rescue medication was significantly more commonly used in HCPtreated attacks than for self-treated attacks ( 23.7 vs. $16.5 \%$, respectively; $p=0.0397)$. Similarly, excluding the 2 outliers reduced C1-INH use to $31.6 \%$ of the attacks requiring rescue medication following self-administration of icatibant, but did not change the HCP-treated result (25.5\%). One possible explanation for the lower rescue medication use for self-treated attacks may simply be that HCPs have easier access to rescue medications than patients selftreating at home.

A substantial number of attacks occurred in patients using a variety of LTP drugs, the most common being danazol (46.1\%), tranexamic acid (22.6\%) and stanozolol (20.7\%). As patients prescribed LTP are more likely to have experienced frequent or severer attacks than patients who do not receive LTP, the higher proportion of self- than HCP-treated attacks among patients using LTP may be related to the increased experience and awareness among these patients.

Time to administration was significantly shorter with self-treated than with HCP-treated attacks, as might be expected given that time to treatment by an HCP must by necessity include travel time for either the HCP or the patient. However, in contrast to previously reported data for the IOS study [20], this updated analysis did not find any significant differences between self- and HCP administration in terms of attack duration and time to resolution. A likely explanation for this is the reduction in time to treatment for HCP-administered icatibant since 2009 ( 8.0 vs. $3.0 \mathrm{~h}$ for self-administration) to $2.0 \mathrm{~h}$ for both HCP and self-administration in 2012. This perhaps reflects the adoption of updated guidance recommending treatment as early as possible $[1,3,13,14]$. Alternatively, it may also represent an increased awareness and recognition of HAE attacks on the part of both the HCP and the patient or reflect positive experiences with a previous administration of icatibant. Whatever the reasons, this finding demonstrates that a shift in approach to the management of acute attacks of HAE has occurred in recent years. Early treatment will directly reduce the total attack duration, and it has been suggested that early treatment may result in quicker symptom resolution and a reduced quality-of-life burden for patients $[3,13,15,20,22,24-$ 26].

The real-world effectiveness of icatibant observed in the IOS in terms of attack duration and time to resolution is comparable to the efficacy reported in the FAST phase III clinical study programme $[16,27,28]$, demonstrating that the clinical study results transfer well to daily practice. In the FAST trials, all icatibant was HCP administered, so the finding that effectiveness data from the IOS, in which the majority of attacks were self-treated, is com- 
parable to the phase III results demonstrates that the introduction of self-administration provides a viable option for the treatment of HAE attacks. Similarly, icatibant is generally well tolerated, and no new safety concerns have been observed in the IOS study to date. Indeed, the rate of AEs, particularly local injection site reactions, is lower than that observed in clinical studies $[16,27]$. This may be due to patients learning to reduce injection site reactions by injecting slowly; however, it is also conceivable that it may be due to the differences in the methods of data collection (HCP-recorded in clinical studies vs. patient-recorded and reported at routine visits in the IOS), which may result in reactions not being consistently recorded in real-world practice.

The method of data collection could be considered a limitation of the current analysis: as the data for the IOS were collected retrospectively at regular clinic appointments, this may have affected the accuracy of the reporting despite many patients using attack diaries. However, as data collection was identical in both groups this should not have adversely influenced the comparison of self- and HCP-treated attacks.

In conclusion, the IOS registry has permitted the evaluation of icatibant self-administration in a real-world setting, building on findings from phase III clinical trials. Self-administration of icatibant enables a shorter time to administration compared with administration by an $\mathrm{HCP}$, and earlier icatibant administration resulted in faster attack resolution. Furthermore, the increase in self-administration over time demonstrates that self-administration is convenient and accepted by patients, and indicates that international guidance is being adopted. Taken together, the results from this analysis demonstrate that self-administration of icatibant is an appropriate, welltolerated and effective method for managing HAE attacks.

\section{Acknowledgements}

\section{IOS Study Group}

Austria: Aberer W.; Denmark: Bygum A.; France: Blanchard Delauny C., Boccon-Gibod I., Bouillet L., Fain O., Gompel A., Jeandel P.-Y., Kanny G., Launay D., Maillard H., Martin L., Olivier Y.; Germany: Baş M., Bork K., Maurer M.; Greece: Psarros F.; Israel: Graif Y., Toubi E.; Italy: Arcoleo F., Bova M., Marone G., Montinaro V., Zanichelli A.; Spain: Baeza M.L., Caballero T., Guilarte M., Hernandez Fernández de Rojas D., Hernando de Larramendi C., Lleonart R., Marques L.; Sweden: Bjoerkander J.; UK: Helbert M., Longhurst $\mathrm{H}$.

The following IOS investigators and study staff are also acknowledged for their contributions to the IOS: Austria: Wiednig

M.; France: Coppere B., Guez S., Masseau A.; Germany: Arnolds J.; Italy: Cicardi M., Cillari E., Zito A.; Spain: Caminoa M., Ibáñez E., Lobera T., López Serrano M.C., Sala A.; UK: Lorenzo L.

The IOS Executive Committee: Aberer W., Bouillet L., Caballero T., Longhurst H., Maurer M., Zanichelli A.

\section{Funding}

The IOS study is funded and supported by Shire, Zug, Switzerland. Medical writing support was provided by David Finch, PhD, of Complete Medical Communications, and was funded by Shire.

\section{Disclosure Statement}

Dolores Hernández Fernández de Rojas has participated in clinical trials for Shire and CSL Behring and received fees for speaking and consultancy from Shire and ViroPharma (part of the Shire Group of Companies). Ethel Ibáñez has received research grant support and/or speaker fees from Shire and ViroPharma and has participated in registry studies. Hilary Longhurst has received funding for research, staff support and/or speaker/consultancy fees from Biocryst, CSL Behring, Dyax, Pharming, Shire, SOBI and ViroPharma. Marcus Maurer has received research grant support and/or speaker/consultancy fees from BioCryst, CSL Behring, Dyax, Shire/Jerini AG and ViroPharma. Vincent Fabien is a fulltime employee of Shire, Zug, Switzerland. Werner Aberer has acted as a medical advisor and speaker for CSL Behring and Shire, has received funding to attend conferences and other educational events, and has received donations to his departmental fund and participated in clinical trials for Shire. Laurence Bouillet has received honoraria from CSL Behring, Pharming, Shire and ViroPharma, and her institute has received research funding from CSL Behring and Shire. Andrea Zanichelli has received speaker fees from CSL Behring, Shire, SOBI and ViroPharma, and consultancy fees from CSL Behring, Shire and ViroPharma. Teresa Caballero has received speaker fees from Shire/Jerini AG and ViroPharma, consultancy fees from CSL Behring, Shire/Jerini AG, SOBI and ViroPharma, and funding for travel and meeting attendance from CSL Behring and Shire, and has participated in clinical trials for CSL Behring, Dyax, Pharming and Shire/Jerini AG.

\section{References}

Int Arch Allergy Immunol 2015;167:21-28 DOI: $10.1159 / 000430864$
1 Zuraw B, Banerji A, Bernstein JA, Busse PJ, Christiansen SC, Davis-Lorton M, Frank MM, Li HH, Lumry WR, Riedl M: US Hereditary Angioedema Association Medical Advisory Board 2013 recommendations for the management of hereditary angioedema due to $\mathrm{C} 1$ inhibitor deficiency. J Allergy Clin Immunol Pract 2013;1:458-467.

2 Longhurst $\mathrm{H}$, Cicardi M: Hereditary angiooedema. Lancet 2012;379:474-481.

3 Cicardi M, Bork K, Caballero T, Craig T, Li $\mathrm{HH}$, Longhurst H, Reshef A, Zuraw B: Evidence-based recommendations for the therapeutic management of angioedema owing to hereditary $\mathrm{C} 1$ inhibitor deficiency: consensus report of an international working group. Allergy 2012;67:147-157.
Self- versus HCP Administration of

Icatibant: Real-World Data 
4 Ghazi A, Grant JA: Hereditary angioedema: epidemiology, management, and role of icatibant. Biologics 2013;7:103-113.

5 Zilberberg MD, Nathanson BH, Jacobsen T, Tillotson G: Descriptive epidemiology of hereditary angioedema hospitalizations in the United States, 2004-2007. Allergy Asthma Proc 2011;32:248-254.

6 Bork K, Siedlecki K, Bosch S, Schopf RE, Kreuz W: Asphyxiation by laryngeal edema in patients with hereditary angioedema. Mayo Clin Proc 2000;75:349-354.

7 Bork K, Hardt J, Schicketanz KH, Ressel N: Clinical studies of sudden upper airway obstruction in patients with hereditary angioedema due to $\mathrm{C} 1$ esterase inhibitor deficiency. Arch Intern Med 2003;163:1229-1235.

8 Bork K, Hardt J, Witzke G: Fatal laryngeal attacks and mortality in hereditary angioedema due to C1-INH deficiency. J Allergy Clin Immunol 2012;130:692-697.

9 Donaldson VH: Kinin formation in hereditary angioneurotic edema (HANE) plasma. Int Arch Allergy Appl Immunol 1973;45:206-209.

10 Fields T, Ghebrehiwet B, Kaplan AP: Kinin formation in hereditary angioedema plasma: evidence against kinin derivation from $\mathrm{C} 2$ and in support of 'spontaneous' formation of bradykinin. J Allergy Clin Immunol 1983;72: 54-60.

11 Maurer M, Bader M, Bas M, Bossi F, Cicardi M, Cugno M, Howarth P, Kaplan A, Kojda G, Leeb-Lundberg F, Lotvall J, Magerl M: New topics in bradykinin research. Allergy 2011; 66:1397-1406.

12 Kaplan AP, Joseph K, Silverberg M: Pathways for bradykinin formation and inflammatory disease. J Allergy Clin Immunol 2002;109: 195-209.

13 Craig T, Aygören-Pürsün E, Bork K, Bowen T, Boysen H, Farkas H, Grumach A, Katelaris $\mathrm{CH}$, Lockey R, Longhurst H, Lumry W, Magerl M, Martinez-Saguer I, Ritchie B, Nast A, Pawankar R, Zuraw B, Maurer M: WAO guideline for the management of hereditary angioedema. World Allergy Organ J 2012;5: 182-199.

14 Longhurst HJ, Farkas H, Craig T, AygörenPürsün E, Bethune C, Bjorkander J, Bork K,
Bouillet L, Boysen H, Bygum A, Caballero T, Cicardi M, Dempster J, Gompels M, Gooi J, Grigoriadou S, Huffer U, Kreuz W, Levi MM, Long J, Martinez-Saguer I, Raguet M, Reshef A, Bowen T, Zuraw B: HAE international home therapy consensus document. Allergy Asthma Clin Immunol 2010;6:22.

15 Caballero T, Sala-Cunill A, Cancian M, Craig TJ, Neri S, Keith PK, Boccon-Gibod I, Bethune C, Bork K: Current status of implementation of self-administration training in various regions of Europe, Canada and the USA in the management of hereditary angioedema. Int Arch Allergy Immunol 2013; 161(suppl 1):10-16.

16 Cicardi M, Banerji A, Bracho F, Malbran A, Rosenkranz B, Riedl M, Bork K, Lumry W, Aberer W, Bier H, Bas M, Greve J, Hoffmann TK, Farkas H, Reshef A, Ritchie B, Yang W, Grabbe J, Kivity S, Kreuz W, Levy RJ, Luger T, Obtulowicz K, Schmid-Grendelmeier P, Bull C, Sitkauskiene B, Smith WB, Toubi E, Werner S, Anne S, Bjorkander J, Bouillet L, Cillari E, Hurewitz D, Jacobson KW, et al: Icatibant, a new bradykinin-receptor antagonist, in hereditary angioedema. N Engl J Med 2010;363: 532-541.

17 Lumry WR, Li HH, Levy RJ, Potter PC, Farkas H, Moldovan D, Riedl M, Li H, Craig T, Bloom BJ, Reshef A: Randomized placebocontrolled trial of the bradykinin $\mathrm{B}(2)$ receptor antagonist icatibant for the treatment of acute attacks of hereditary angioedema: the FAST-3 trial. Ann Allergy Asthma Immunol 2011;107:529-537.

18 Shire: Firazyr $30 \mathrm{mg}$ solution for injection in pre-filled syringe - summary of product characteristics. http://www.medicines.org. uk/emc/medicine/21761/SPC/Firazyr+ $30+\mathrm{mg}+$ solution + for + injection + in + pre filled+syringe/ (accessed February 24, 2014).

19 Firazyr (icatibant). US prescribing information, August 2011.

20 Maurer M, Aberer W, Bouillet L, Caballero T, Fabien V, Kanny G, Kaplan A, Longhurst $\mathrm{H}$, Zanichelli A: Hereditary angioedema attacks resolve faster and are shorter after early icatibant treatment. PLoS One 2013;8: e53773.
21 Aberer W, Maurer M, Reshef A, Longhurst H, Kivity S, Bygum A, Caballero T, Bloom BJ, Nair N, Malbrán A: Open-label, multicenter study of self-administered icatibant for attacks of hereditary angioedema. Allergy 2014; 69:305-314.

22 Tourangeau LM, Castaldo AJ, Davis DK, Koziol J, Christiansen SC, Zuraw BL: Safety and efficacy of physician-supervised selfmanaged $\mathrm{C} 1$ inhibitor replacement therapy. Int Arch Allergy Immunol 2012;157:417-424.

23 Blasco AJ, Lazaro P, Caballero T, Guilarte M Social costs of icatibant self-administration vs. health professional-administration in the treatment of hereditary angioedema in Spain. Health Econ Rev 2013;3:2.

24 Caballero T, Aygören-Pürsün E, Bygum A, Beusterien K, Hautamaki E, Sisic Z, Wait S, Boysen HB: The humanistic burden of hereditary angioedema: results from the Burden of Illness Study in Europe. Allergy Asthma Proc 2014;35:47-53.

25 Lumry WR, Castaldo AJ, Vernon MK, Blaustein MB, Wilson DA, Horn PT: The humanistic burden of hereditary angioedema: impact on health-related quality of life, productivity, and depression. Allergy Asthma Proc 2010;31:407-414.

26 Lang DM, Aberer W, Bernstein JA, Chng HH, Grumach AS, Hide M, Maurer M, Weber R, Zuraw B: International consensus on hereditary and acquired angioedema. Ann Allergy Asthma Immunol 2012;109:395-402.

27 Lumry W, Levy R, Li H, Farkas H: Icatibant for the treatment of repeated attacks of hereditary angioedema: FAST-3 trial open-label extension study phase (poster No 631). European Academy of Allergy and Clinical Immunology (EAACI)-World Allergy Organization (WAO) Congress, Milan, June 22-26, 2013.

28 Bas M, Greve J, Hoffmann TK, Reshef A, Aberer W, Maurer M, Kivity S, Farkas H, Floccard B, Arcoleo F, Martin L, Sitkauskiene B, Bouillet L, Schmid-Grendelmeier P, Li H, Zanichelli A: Repeat treatment with icatibant for multiple hereditary angioedema attacks: FAST-2 open-label study. Allergy 2013;68: 1452-1459. 